\title{
The Phenotypic and Cytogenetic Spectrum of Partial Trisomy 9
}

\author{
Golder N. Wilson, Anita Raj, and Diane Baker \\ Section of Pediatric Genetics, Department of Pediatrics, University of Michigan, \\ Ann Arbor, Michigan
}

\begin{abstract}
A new patient with trisomy for the chromosome segment 9 pter $\rightarrow \mathrm{q} 22$ is compared to 19 previously reported cases of partial trisomy 9. Manifestations such as microcephaly, prominent nasal root, bulbous nose, and down-turned corners of the mouth are common to patients with trisomic segments extending from $9 \mathrm{p} 21$ to $9 q 13$, while intra-uterine growth retardation, cleft lip/palate, skeletal anomalies, and heart defects are more common with trisomic segments extending through 9q22-9q32. A graphic method illustrates this progression in the partial trisomy 9 malformation spectrum as the triplicated chromosome region extends from bands $9 \mathrm{p} 21$ to $9 \mathrm{q} 32$. More severe and random defects are observed with complete trisomy 9 or tetrasomy $9 p$, suggesting an extreme excess of material greatly increases developmental variability.
\end{abstract}

Key words: Rethoré syndrome, partial Trisomy 9, multiple congenital anomalies/mental retardation (MCA/MR) syndrome

\section{INTRODUCTION}

Since the description by Rethoré et al [1973] of a characteristic syndrome due to partial trisomy 9, over 150 reports of partial [Young et al, 1982] or complete [Annerén and Sedin, 1981] trisomy 9 have appeared. We report on a new case of partial trisomy 9 and discuss the phenotypic and cytogenetic correlations now possible for trisomy 9 disorders.

\section{CLINICAL REPORT}

The propositus was born at term after an uncomplicated pregnancy to a 36-yearold mother with a history of 5 first trimester abortions by her current husband and 2

Received for publication January 19, 1984; revision received June 14, 1984.

Address reprint requests to Golder N. Wilson, M.D., Ph.D., Department of Pediatrics, K2015 Holden, University Hospitals, Ann Arbor, MI 48109.

(C) 1985 Alan R. Liss, Inc. 
healthy children by a previous marriage. At 10 hours the infant had a weight of 2.0 $\mathrm{kg}(<3 \mathrm{rd}$ centile) and a length of $44 \mathrm{~cm}$ ( $<3 \mathrm{rd}$ centile). There was microcephaly (OFC $30.5 \mathrm{~cm}$, <3rd centile) with abnormally wide sutures. The child had an abnormal facial appearance (Fig. 1A) with an antimongoloid slant of palpebral fissures, bulbous nose, left unilateral cleft lip and palate, and proportionate hypertelorism with an inter-pupillary distance of $3.8 \mathrm{~cm}$ (50th centile). The ears were anteverted and anteflexed with prominent helices. There was no cardiac murmur and the kidneys had a normal contour. There was a simian crease on the right palm and a single crease on each fifth digit with clinodactyly. There were simple arch patterns on all fingers and hypoplastic nails on hands and feet. The feet had a rocker-bottom appearance with metatarsus adductus bilaterally. The serum immunoglobulin A level was less than $3.8 \mathrm{mg} \%$ and the immunoglobulin $M$ level was $5.1 \mathrm{mg} \%$ (normal). Skeletal survey: bilateral acromioclavicular synostosis and calcifications in the right upper quadrant suggestive of meconium peritonitis. A chest radiograph showed an enlarged heart with prominent pulmonary vasculature. The child died at 36 hours due to cardiorespiratory failure; autopsy was not permitted.

\section{RESULTS AND DISCUSSION}

Figure 1B shows the patient's 9 chromosomes as obtained from the peripheral blood karyotype $(47, \mathrm{XX},+9$ pter $\rightarrow \mathrm{q} 22$ :) using GTG staining. The extra chromosome was identified as 9 pter $\rightarrow \mathrm{q} 22$ : based on its asymmetric appearance by both GTG and CTG banding. The mother's chromosomes were normal; the father refused to be studied.

As summarized in Table I, the patient's manifestations resemble those of 19 previous cases of partial trisomy 9 , of which 8 were de novo occurrences and 11 occurred by 3:1 nondisjunction from a maternal translocation. The extra chromosome in our case may have been derived from a paternal translocation based on the history of miscarriage but the father refused analysis. The preponderance of females (14 of 20) with partial trisomy 9 has been noted as a general characteristic of partial trisomy 9 [Young et al, 1982] suggesting that males are generally more severely affected with higher likelihood of prenatal death.

A spectrum of clinical severity which correlates with the extent of triplicated chromosome 9 material can be derived by inspection of Table I. Mental retardation is virtually a constant feature. Lewandowski et al [1976] emphasized that partial trisomy 9pter $\rightarrow$ p21: patients have mild facial anomalies and few skeletal or visceral anomalies. The summary of partial trisomy 9 pter $\rightarrow$ p11: patients provided by Young et al [1982] includes the patients of Lewandowski et al [1976] and a slight background of phenotypic effects due to unbalanced reciprocal translocations; this large number of patients has the typical face described by Rethoré et al [1973], i.e., microcephaly, enophthalmos, hypertelorism, antimongoloid slant of palpebral fissures, broad nasal root with a bulbous nasal tip, down-turned corners of the mouth, and anomalous ears. Partial trisomy 9pter $\rightarrow$ q11-13: patients also have the typical face seen in the Rethoré syndrome with an increased incidence of skeletal and heart defects. Tetrasomy $9 p$ patients [Balestrazzi et al, 1983], have a similar facial appearance but are more severely affected; $33 \%$ have died in the first year and six of 10 had hydrocephalus (Table I). Partial trisomy 9pter $\rightarrow$ q22-32: patients, as exemplified by our propositus, have the characteristic face with increased incidence of intrauterine growth retarda- 

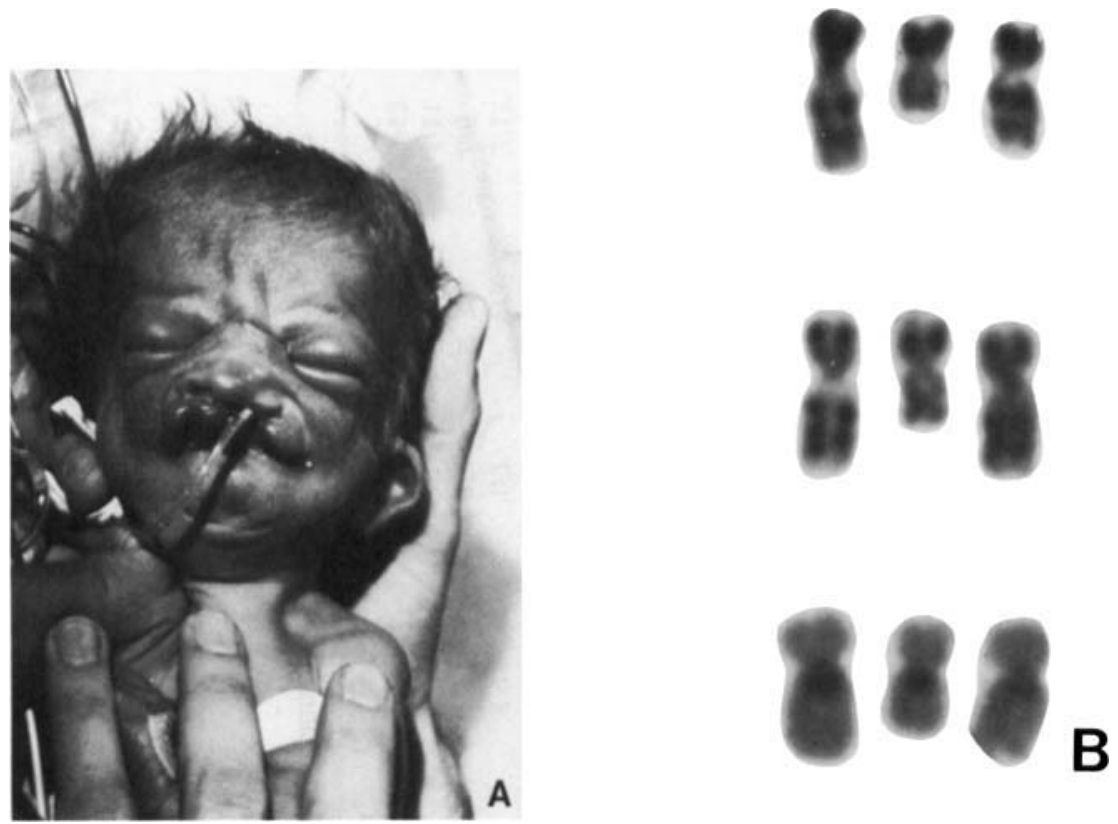

Fig. 1. A. The propositus. B. GTG-banded partial karyotype of propositus demonstrating the extra chromosome interpreted as 9 pter $\rightarrow$ q22: between her two normal 9 chromosomes. The upper two groups are G-banded chromosomes while the lower group is C-banded.

tion, cleft lip/palate, micrognathia, cardiac anomalies, rocker-bottom feet, sacral dimple, and talipes equinovarus or congenital hip dislocation. The two cases of partial trisomy 9q reported by Turleau et al [1975] had a very different face from trisomy 9p patients; this influence of the distal $9 q$ region may explain why complete or mosaic trisomy 9 patients often do not show the characteristic facies of patients with Rethore syndrome. Trisomy 9 patients are more severe and variable in their phenotype than partial trisomy 9 patients, and there is frequent mosaicism. Because of their growth retardation and dermatoglyphic arch patterns [Young et al, 1982], severe cases of partial trisomy 9 may be initially confused with trisomy 18 patients.

The catalogue of triplication 9 patients summarized in Table $I$ is perhaps the best opportunity in man for matching clinical manifestations with a progressive increase of extra chromosome material. Using these data, the incidence of defects is graphically related to the extent of trisomic chromosome 9 in Fig. 2. Each square of the graph is shaded according to the percent of patients having a given defect. At the right is shown the mean percent for the five patient categories; the resulting hierarchy of defects represents the malformation spectrum for partial/complete trisomy 9 patients as a whole. Using this graphical method, there is an obvious progression in malformation spectrum with triplicated chromosome length through band $9 q 32$. The apparent decline in malformations for complete trisomy 9 patients in part reflects the different phenotypic influence of the $9 q$ terminal region described above [Turleau et al, 1975], but also the wide variety of less common defects in these patients which are not listed in Table I. Unusual malformations reported in patients with trisomy 9 


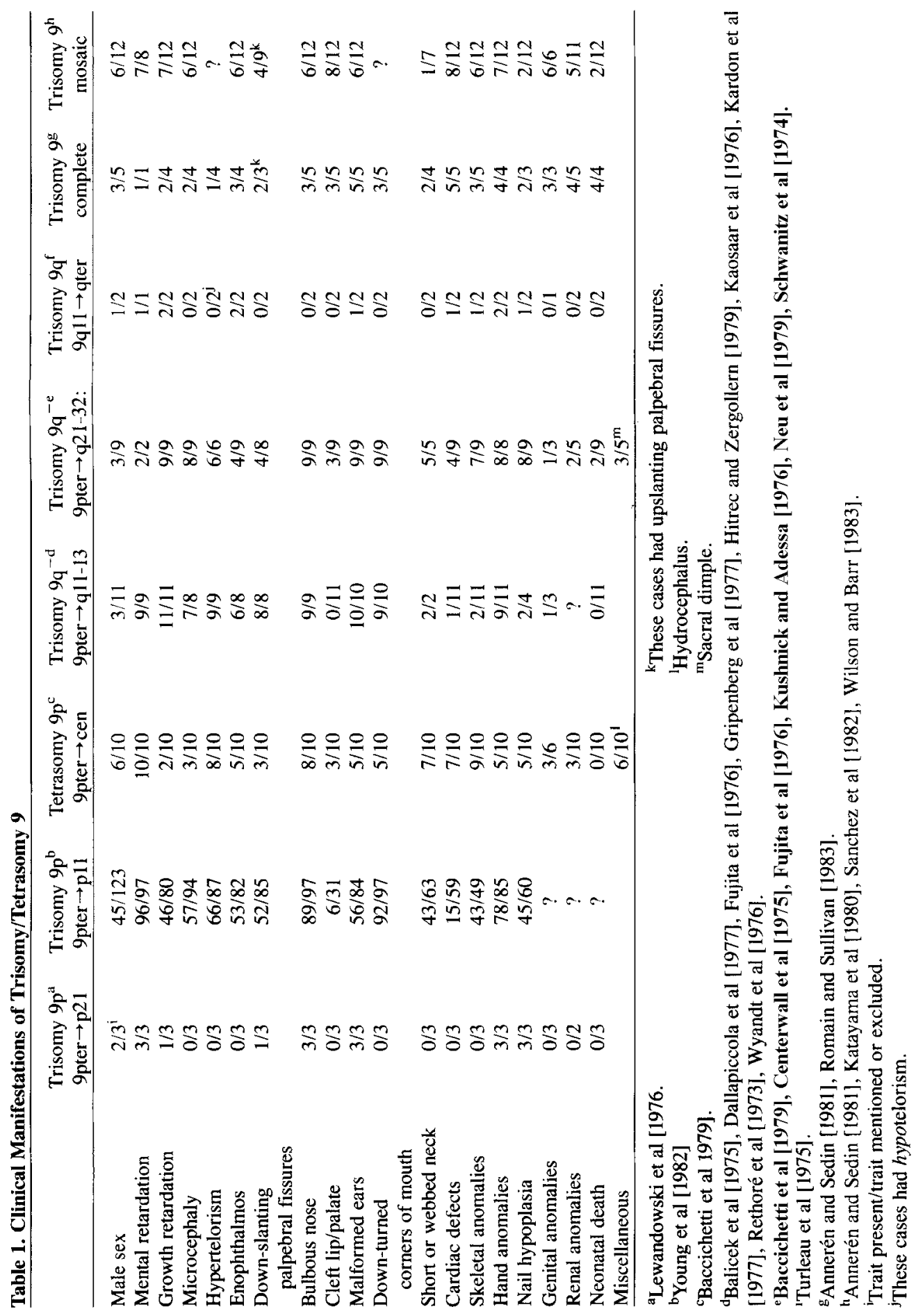




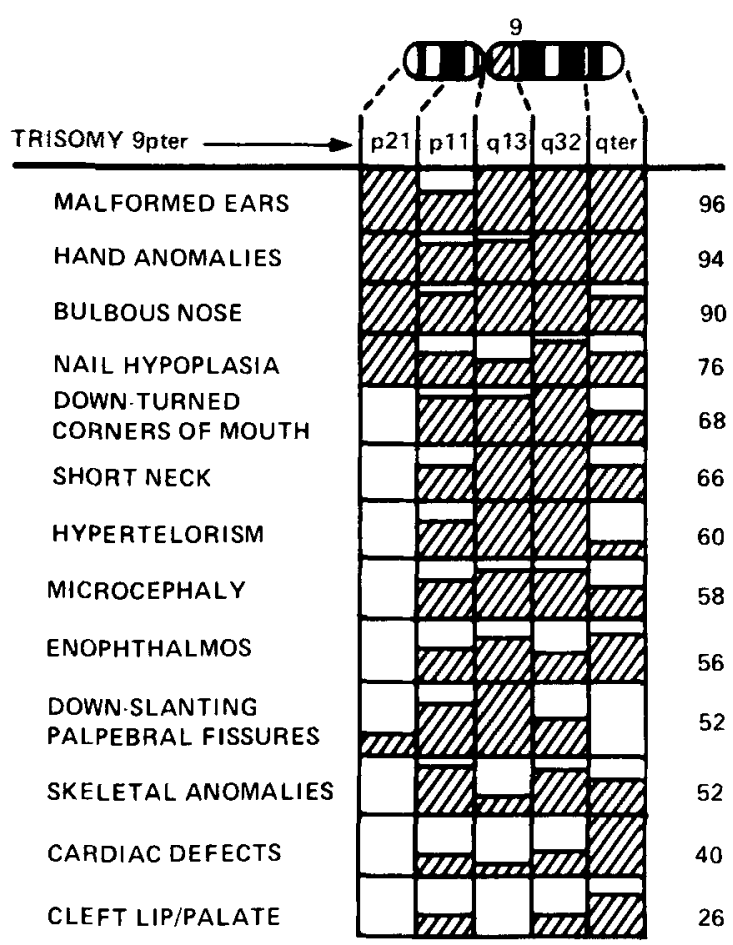

Fig. 2. Graphic display of malformation incidence versus extent of trisomic chromosome 9. Selected data from Table I are expressed as shaded squares representing the percent of defects in a given patient category. At the right is the mean percent for all five patient categories.

include cranial asymmetry and malrotation [Wilson and Barr, 1983], cloverleaf skull and leukomalacia [Katayama et al, 1980], perineal hypoplasia [Annerén and Sedin, 1981], ambiguous genitalia [Sutherland et al, 1976], and many others. In trisomy 9 and tetrasomy $9 \mathrm{p}$ patients an extreme of excess chromosome material seems to be reached that increases the variety and severity of malformation. The progression of findings illustrated by partial/complete trisomy 9 patients supports the hypothesis of Shapiro [1983] that one effect of extra chromosome material is to increase the range of variation permitted for embryologic and homeostatic mechanisms.

\section{REFERENCES}

Annerén G, Sedin G (1981): Trisomy 9 syndrome. Acta Paediatr Scand 70:125-128.

Baccichetti C, Lenzini C, Temperani P, Pallotta R, Giorgi PL, Tarantino E, Mengarda G, Dordi B (1979): Partial trisomy 9: Clinical and cytogenetic correlations. Ann Genet 22:199-204.

Balicek P, Zizka J, Lichy J (1975): A case of trisomy 9p in a family with translocation 9/15. Humangenetik 27:353-358.

Balestrazzi P, Croci G, Frassi C, Franchi F, Giovannelli G (1983): Tetrasomy 9p confirmed by GALT. J Med Genet 20:396-399.

Centerwall WR, Mayeski CA, Cha CC (1975): Trisomy 9q-. A variant of the 9p trisomy syndrome. Humangenetik 29:91-98. 
Dallapiccola B, Mastroiacovo P, Segni G (1977): New autosomal syndromes. Trisomies 4p and 9p. Acta Genet Med Gemellol 26:267-273.

Francke U, Benirschke K, Jones OW (1975): Prenatal diagnosis of trisomy 9. Humangenetik 29:243250.

Frohlich GS (1982): Delineation of trisomy 9. J Med Genet 19:316-317.

Fujita H, Shimazaki M, Takeuchi T, Hayakawa Y, Oura T (1976): 47, $(9 q-)$ in three unrelated children with growth hormone deficiency. Hum Genet 31:271-282.

Gripenberg V, Hongell K, Tivanainen M, Kivimaki T (1977): Free trisomy $9 p$ in an elderly woman. Ann Genet 20:36 40 .

Hitrec V, Zergollern L (1979): Trisomija 9p-Klinickii citogenetski sindrom. Acta Med Iugosi 33:169182.

Kaosaar ME, Mikelsaar AV, Talvik TA, Mikelsaar RV (1976): A case of trisomy for the short arm of chromosome $9(+9 p)$. Hum Genet 34:77-80.

Kardon NB, Salwen HR, Krauss MA, Davis JG, Jenkins EC (1977): De novo trisomy 9pter $\rightarrow$ q13. Hum Genet 37;149-153.

Katayama KP, Wilkinson EJ, Herrmann J, Glaspey JC, Agarwal AB, Roesler MR, Mattingly RF (1980): Clinical delineation of trisomy 9 syndrome. Obstet Gynecol 56:665-668.

Kushnick T, Adessa GM (1976): Partial trisomy 9 with resemblance to Coffin-Siris syndrome. J Med Genet 13:237-239.

Lewandowski RO, Yunis JJ, Lehrke R, O'Leary J, Swaiman KF, Sanchez O (1976): Trisomy for the distal half of the short arm of chromosome 9. Am J Dis Child 130:663-667.

Neu RL, Dennis NR, Lauman JT Jr., Bannerman RM (1979): An infant with trisomy 9pter $\rightarrow 9 q 22$ resulting from 3:1 segregation in a 46,XX,t(1:9)(p36;q22) mother. Ann Genet 22:151-154.

Rethoré MO, Hoehn H, Rott HD, Couturier J, Dutrillaux B, Lejeune J (1973): Analyse de la trisomie 9p par dénaturation menagée. Humangenetik 18:129-138.

Romain DR, Sullivan J (1983): Delineation of trisomy 9 syndrome. J Med Genet 20:156-157.

Sanchez JM, Fittman N, Migliorini AM (1982): Report of a new case and clinical delineation of mosaic trisomy 9 syndrome. J Med Genet 20:384-387.

Schwanitz GV, Schamberger V, Rott HD, Wieczorek V (1974): partial trisomy 9 in the case of familial translocation 8/9 mat. Ann Genet 17:163-166.

Shapiro BL (1983): Down Syndrome-a disruption of homeostasis. Am J Med Genet 14:241-269.

Sutherland GR, Carter RF, Morris LL (1976): Partial and complete trisomy 9: Delineation of a trisomy 9 syndrome. Hum Genet 32:133-140.

Turleau C, deGrouchy J, Chavin-Colin F, Roubin M, Brissaud PE, Repesse G, Safar A, Borniche P (1975): Partial trisomy 9q: a new syndrome. Humangenetik 29:231-241.

Wilson GN, Barr M Jr (1983): Trisomy 9 mosaicism: Another cause for the manifestations of Goldenhar syndrome. J Craniofac Genet Dev Biol 3:313-316.

Wyandt HE, Hecht F, Magenis RE, Wysham DG, Prescott G (1976): 9p trisomy identified by Giemsa11. Hum Genet 31:355-358.

Young RS, Reed T, Hodes ME, Palmer CG (1982): The dermatoglyphic and clinical features of the 9p trisomy and partial 9p monosomy syndromes. Hum Genet 62:31-39.

Edited by John M. Opitz and James F. Reynolds 